\title{
La salud oral en el Perú precolombino - La caries dental en la época precolombina -
}

The oral health in Precolombian Peru before - The dental caries in the Precolombian epoch before -

\section{Resumen}

No se han realizado muchos trabajos de investigación sobre el tema, nuestra intención en el presente articulo es dar un alcance sobre las consideraciones y conclusiones de las mismas. El peruano Precolombino esluvo afectado por patologías odontologías como: carie dental, enfermedad periodontal, abrasión, etc.

La caric dental afecto mas al poblador del litoral que al del ande, esto se debe a que las regiones geográficas presentan diversos factores exógenos como son el clima, la dieta, las costumbres. Conforme avanzamos en el tiempo y las culturas precolombinas alcanzaban mayor auge y desarrollo también aumenta la susceptibilidad a la carie, motivo por el cual se presenta un mayor número de cráneos afectadas por la carie durante el periodo del impero Incaico.

\section{Abstract}

There havent been made much investigación work this item our intention in this article is give an approach about the considerations and conclusions of them The pre Columbian Peruvian habitant was afected, gum descases, abrasion, ctc. Dental caries affected the litoral habitante more than Andean habitant due to the different geographic regiens show diverse exogenic factors such as climate, diet, uses. As we go through in time and the pre colombian cultures got more development, also caries susceptibility increased. That's why there is a greater number of skulls affected by caries during the inca empire perod.

\section{Introducción}

Existen pocos trabajos de investigación en este campo de la odontoantropología, quizá por la dificultad de obtener la muestra o tal vez por la idoneidad de la misma; estos cráneos en su mayoría se encuentran bajo la protección y conservación del museo de antropología y arqueología de Pueblo Libre.

La mayor parte de los trabajos de investigación los han realizado con muestras tomadas de la costa central y sur del pars. En estos trabajos se ha demostrado que las patologías odontológicas que afectan al Perú Precolombino son las mismas que afectan al Perú de estos días: caries dental periodontopatías, abrasión, etc. ${ }^{1,2, j, 4}$

En este articulo nos ocuparemos de la carie dental de la cual el antiguo peruano no se eximió; siendo variada cuantitativamente en las diferentes regiones gengráficas del país y estaba condicionada a factores exógenos como la alimentación, el clima y las costumbres. ${ }^{1 \hat{j}}$ De esta manera encon-

\section{ARTículo DE Revisión}

\section{César Andrés Borja Villanueva1"; Luis H. Gálvez Calla ${ }^{2 *}$}

\section{Bachiller en Odontología}

Instituto de investigación Estomatologica, Departamento Académico deCiencias Básicas

* Facultad de Odontología, Universidad Nacional Mayor de San Marcos, Lima, Perú E-mail: Igalvezc@unmsm.edu.pe

Palabras clave: odonto antropología, Precolombino, caries dental, abrasión.

Key words: odontoanthropology, precolombian, dental caries, abrasion.

tramos que los pobladores del ande eran menos susceptibles a la carie con respecto a los pobladores del litoral y los pobladores de la selva.

Las investigaciones realizadas por el Dr. Valdivia Vera ${ }^{5}$ en su libro «Odontoantropología Peruana» hacen notar que cuando la población se asentaba en las alturas eran menos propensas a la carie y cuando bajaban hacia el nivel del mar aumentaba a susceptibilidad a la carie.

Cuando observamos y comparamos las arcadas de un poblador la costa y uno de la sierra, el primero presenta más lesiones cariosas, pero en el segundo es frecuente encontrar piezas abrasionadas; esto se explicaría por el tipo de dieta del poblador del ande, ya que este consumía alimentos semicrudos y duros como el charqui, la quinua, la cancha y la mazorca, etc. Este consumo de alimentos duros generaba un esfuerzo fisiológico masticatorio y por consiguiente mayor salivación, así también no debemos de olvidar el consumo de hoja de coca que lo mezclaban con la llujta, elemento abrasivo pero que aumentaban el $\mathrm{pH}$. salival; entonces podríamos decir que sus alimentos eran factores dietéticos protectores contra la carie.

El Dr. Valdivia ${ }^{5}$ señaló la importancia que tendría el agua en la susceptibilidad a la carie, ya que las aguas de los ríos en el lugar de su origen se encontrarían en mejor estado de mineralización y que las culturas que se asentaban cerca de allí presentaban dientes duros y blancos (collahuas y aymaras) no así los que se alejaban del origen del río que presentan dientes débiles y amarillos (Ancón y Makat - Tampu)

Respecto a las culturas del litoral, los cráneos de la costa central son las más afectadas y esto podría deherse al poco tiempo de exposición a los rayos solares a diferencia de las culturas del norte y sur de la costal.

Durante mucho tiempo se pensó que el antiguo poblador peruano era inmune a la carie dental; esto se sus- 
tentaba a que en los cráneos exhibidos en los vitrales de los museos no presentaban lesiones cariosas evidentes y que además el odontólogo no participa en los trabajos de investigación antropológicos.

Las lesiones cariosas en estos cráneos se ubican con mayor frecuencia en las zonas interproximales y cervicales debido a la facilidad con que se acumula la placa bacteriana en esas zonas y por lo difícil de su remoción; las caras oclusales también se encuentran afectadas pero en menor proposición debido quizá a los mecanismos de abrasión ${ }^{2}$.

Las lesiones cariosas se presentan con más frecuencia en cráneos de edad adulta, en ambos sexos y especialmente en las primeras molares de la arcada derecha ${ }^{1}$.

El antiguo poblador peruano al margen de su ubicación geográfica, convivió en armonía con la naturaleza y supo explotar para su beneficio los suelos que su región le brindaba; cuaindo uno aprecia un cráneo precolombino de la costa o sierra vera que poseían dentadura bien implantada en sus alvéolos, sólidas mandíbulas, estructura óseo alveolar e inserciones musculares vigorosas. El poblador peruano de aquella época padeció de carie dental, pero estuvieron monos afectados que nuestra población actual.

Conforme nuestros antepasados alcanzaban mayor desarrollo y se consistían en civilizaciones prosperas también aumentaba su susceptibilidad a la carie dental y otras enfermedades; se puede apreciar que las culturas locales con menos desarrollo presentan menor número de cráneos afectados que las panculturas como la Paracas. También se puede decir que las culturas de mas antigüedad eran menos susceptibles a la carie, a diferencia de las culturas actuales como la Inca6.

Durante el Imperio Incaico el desarrollo de las artes, la agricultura y la ingeniería fue espectacular; pero también el avance de las enfermedades y por ende de la carie dental y asi lo reportan los estudios realizados en cráneos del periodo Inca. Probablemente el avance de las enfermedades durante el Incanato se debió al intenso intercambio cultural y social entre los pobladores del ande, el litoral y la selva favorecidos por la construcción de caminos que acortan el límite del incario ${ }^{6}$

Analizaremos como hecho importante el traslado de las mujeres a los acllahuasis para ser usadas como virgenes del sol, del Inca o mujeres de la nobleza, el uso de los varones de los pueblos para la construcción de edificios estatales, el traslado de los hijos de los curacas al cuzco para su quechuización, los dioses de los curacas convertidos en dioses menores y sobre todo el traslasdo de animales, recursos marinos, vegetales y recursos minerales.

Pero a pesar de ello la población del Incario estaba menos afectada que la muestra actualmente; citare algunas palabras de Luis. E. Valcarcel" sobre este tema: "Los dietistas de aquellos tiempos combinaron a base de vegetales la ración vital para lograr una buena salud y capacidad de resistencia a las adversidades...." Este mismo autor, en relación con la alimentación en el antiguo Perú expresa lo siguiente: «fueron los incas fílosofos del alimento, toda su vida cultural giro en torno a él. Gracias a su sabia organización el Perú gozo de varios siglos de bienestar".

\section{Conclusiones}

- La carie dental estuvo presente en el Perú precolombino pero en menor proporción que en el Perú de hoy

La carie dental en el Perú Precolombino afecta más a los pueblos del litoral y la selva que a los pueblos del ande.

- Las lesiones cariosas se ubican frecuentemente en las zonas interproximales y cervicales.
- El desarrollo y expansión de las culturas genero una mayur susceptibilidad a la carie dental

- La alimentación del antiguo poblador peruano jugó un rol importante como factor dietético protector.

- La carie dental estuvo presente con mayor frecuencia en cráneos de edad adulta y en ambos sexos.

\section{Referencias}

1.Vásquez Soto, F. Contribución al estudio objetivo radiográfico de la caries dental y lesiones periapicales en cráneos de momias del antiguo Perú. Estudio descriptivo. 1961. Tesis Bach. UNMSM. 101p.

2.Alcalde Sánchez, A. Estudio antropológico para determinar la posible situación del estado de salud bucal en 112 cráneos de las culturas prehispánicas Paracas, nazca y de los pobladores del valle de Ancón. Estudio descriptivo, Lima, 1986, Tesis Bach. UPCH 52p.

3.Dabbert Drofdovsky, Alexandra Contribución histórico - comparada al estudio de los dientes de los antiguos habitantes del Perú. Estudio Descriptivo, Lima, 1951, Tesis Bach. UNMSM.

4.Gilberto Domínguez del Río Historia de la práctica odontológica en el Perú. Revistas visión dental, IV(15), 2001, 31-33.

5.Valdivia Vera, L. Odontoantropología Peruana CONCYTEC. Lima, 1981.

6.Del Busto Durthurburu Perú Incaico. 7ma Edición Lima - Perú, 1988.

7.Valcarcel Luis E. Historia del Perú Antiguo. Lima, 1964 